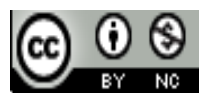

Jurnal Pendidikan Dasar Indonesia is licensed under

A Creative Commons Attribution-Non Commercial 4.0 International License

\title{
PEMENUHAN ASPEK AFEKTIF SISWA SEKOLAH DASAR DALAM PEMBELAJARAN JARAK JAUH MELALUI KOMITMEN BELAJAR PADA MASA PANDEMI COVID-19
}

\author{
Titim Kurnia ${ }^{1)}$, Yudha Andana Prawira ${ }^{2)}$ \\ 1) Dinas Pendidikan, Kota Bandung, Indonesia \\ E-mail:75titimkurnia@gmail.com \\ ${ }^{2)}$ Balai Diklat Keagamaan Bandung, Bandung, Indonesia \\ E-mail:yudania3@gmail.com
}

\begin{abstract}
Abstrak. Dampak pandemic covid-19 dalam dunia pendidikan di Indonesia sangat luar biasa. Pembelajaran online yang semula banyak ditolak penerapannya, saat ini justru mendapatkan pembenaran. Keraguan terhadap pembelajaran online bahwa pembelajaran online hanya bermakna untuk pengembangan kognitif. Penelitian ini justru membantah asumsi tersebut, bahwa dengan pembelajaran online bisa juga mengembangkan aspek afektif siswa. Penggalian data melalui angket terhadap orang tua siswa, wawancara dengan guru, serta observasi terhadap kegiatan yang dilakukan siswa. Analisis data dimulai dengan reduksi data dalam bentuk pengolahan data responden yang berupa data ordinal menjadi data interval dengan methode succeesive interval. Hasil penelitian menunjukkan bahwa baik dari respon orang tua maupun siswa sangat positif. Sebagai contoh siswa yang semula masih bersikap lambat dan negatif sebanyak $60 \%$, setelah mengikuti pembelajaran jarak jauh yang didahului dengan komitmen belajar, menjadi sekitar 30\% siswa yang masih berperilaku negative. Studi ini menemukan keberhasilan sebagaimana yang telah dikemukakan di atas yaitu dalam perubahan sikap siswa yang menjadi lebih baik walaupun pembelajaran jarak jauh dilaksanakan secara asinkronus. Kajian ini memperlihatkan adanya masalah yang perlu diselesaikan yaitu mengefektifkan dan mengefisienkan pembelajaran jarak jauh dalam mencapai kompetensi siswa baik kognitif, afektif, maupun psikomotor. Namun demikian, penelitian ini masih memiliki keterbatasan karena itu, masih dibutuhkan penelitian lanjutan untuk melengkapi dan meningkatkan akurasi dan signifikansi sehingga bisa digeneralisasikan
\end{abstract}

Keyword: afektif; pandemic Covid-19; pembelajaran jarak jauh

\begin{abstract}
The COVID-19 pandemic has enormously affected educational system in Indonesia. Distance learning, initially rejected by many learners, is now justified. Many believe online learning can highly enhance cognitive development, yet doubts emerge. This research actually refutes this hypothesis as online learning can also develop emotional aspects on students. Data mining is conducted through questionnaires to parents, interviews with teachers, and student activities' observation. Data analysis begins with reducing the data in form of processing respondents from ordinal into interval data using successful interval method. The results showed that responses from parents and students were very positive. $60 \%$ of students were slow and negative at first, but after participating distance learning preceded by a commitment to learn, it turned into around $30 \%$. This study is considered success to change students' attitudes better, though distance learning was done asynchronously. There are problems to solve to make distance learning effective and efficient in terms of acquiring students' cognitive, affective, and psychomotor skills. This research still has limitations, thus conducting further researches are expected to complete and increase its accuracy and importance so that it can be generalized.
\end{abstract}

Keyword: afectives; distance learning; pandemic Covid-19

\section{PENDAHULUAN}

Pandemi Covid-19 telah membawa akibat yang meluas dan mendasar terhadap dunia pendidikan. Pembelajaran jarak jauh yang semula ditolak penerapannya justru mendapatkan pembenaran untuk diterapkan. Sejumlah penelitian melihat pembelajaran online memiliki keterbatasan karena lebih menekankan dimensi kognitif, mengabaikan dimensi afektif, sebagaimana yang diungkapkan (Gazali, 2018) dan (Lestari, 2020). Akibat negative dari pembelajaran jarak jauh juga 
menjadi temuan penelitian dari penelitian [1] khususnya dengan melihat pembelajaran jarak jauh dari aspek interaksi guru-murid yang menghilang. Fakta tentang pembelajaran jarak jauh memiliki kemampuan dalam memenuhi dimensi afektif cenderung masih diabaikan dalam studi-studi yang ada. Studi Farisi menyebutkan bahwa pembelajaran jarak jauh dapat pula turut membangun karakter bangsa [2] bahkan menegaskan bahwa pendidikan berbasis jarak jauh menjauhkan nilai-nilai dari siswa karena mengutamakan kompetensi yang bersifat kognitif.

Pentingnya dimensi kognitif tidak dapat dihindari. Pandangan Farisi menunjukkan bahwa dimensi afektif merupakan kompetensi dasar siswa yang memberi pengaruh pada kehadirannya dalam lingkungan social, bahwa karakter ini dipandang sangat mendasar untuk mengantisipasi fenomena "inclusion of social intercourse " sebagai konsekuensi dari situasi keterpisahan secara fisik dan sosial dengan yang lain. Sebuah fenomena sosio-psikologis yang dipandang sebagai variable hilangnya orientasi diri, distraksi, atrisi, non-aktif [2]. Kritik terhadap pembelajaran online yang mengabaikan dimensi afektif bersumber pada dua alasan. Pertama, sangat sulit penyelenggaraan pembelajaran jarak jauh untuk membangun karakter atau afektif, sebagaimana diungkapkan [3]. Kedua, kesulitan lainnya dalam pembelajaran jarak jauh juga dalam hal interaksi dan penggunaan media, hal ini sesuai dengan penelitian [4]. Tulisan ini menunjukkan bahwa kedua alasan tersebut tidak memiliki dasar yang cukup karena dimensi afektif bisa juga dicapai melalui pembelajaran jarak jauh, sebagaimana yang saat ini menjadi kebutuhan yang mendesak dalam perkembangan dunia Pendidikan nasional. Tulisan menunjukkan bahwa nilai-nilai afektif diperoleh siswa dari pembelajaran tersebut merupakan dampak pembelajaran jarak jauh sebagai pengganti pembelajaran tatap muka. Hal ini tentu saja membutuhkan adaptasi dari beragam pihak untuk penanganan situasi ini. Sebagaimana yang dikemukakan [5] dan [6].

Tulisan ini didasarkan pada satu argument bahwa keberhasilan pembelajaran dalam memenuhi kebutuhan kompetensi afeksi dapat diperoleh melalui pembelajaran jarak jauh secara asinkronus dengan didahului oleh komitmen belajar. Kegiatan pembelajaran jarak jauh yang dilakukan secara sinkronus maupun asinkronus berdampak positif pada aspek afektif siswa. Sebagaimana penelitian yang telah dilakukan [7] dan [8]. Sehingga saya berpendapat bahwa pembelajaran jarak jauh dengan segala keterbatasannya, masih dianggap dapat pula meningkatkan kompetensi peserta didik pada ranah afektif.

Dari beberapa penelitian yang membahas tentang efektivitas pembelajaran jarak jauh selama masa pandemic Covid-19 ada beragam hambatan dalam menyelenggarakan pembelajaran jarak jauh, sebagaimana yang telah diungkap penelitian [9] kendala perangkat dan jaringan memiliki pengaruh terhadap keberhasilan pembelajaran jarak jauh [9], demikian pula yang disampaikan [10], [11], [3], dan [5]. Penelitian mereka menyatakan bahwa walaupun peneliltiannya menunjukkan sesuatu yang positif, namun masih mengalami beberapa kekurangan. Sebagai contoh hasil penelitian Jamaluddin menungkapkan kelemahan pada piranti atau infrastruktur yang bisa menghambat keberhasilan pembelajaran jarak jauh ini [9]. Berbeda dengan penelitiannya [11] yang mengungkapkan bahwa yang bisa menghambat keberhasilan pelaksanaan pembelajran jarak jauh ini adalah faktor guru.

Sementara itu, ada penelitian lain yang menelaah tentang perlunya komitmen belajar dalam proses pembelajaran, menunjukkan hasil yang positif antara lain yang dikemukakan oleh [12], [13], dan [14], yang menyatakan bahwa untuk mengetahui pengaruh sikap peserta didik terhadap prestasi belajar dan untuk mengetahui pengaruh komitmen diri peserta didik terhadap prestasi belajar, demikian pula komitmen guru terhadap siswa. Kajian-kajian tersebut, peneliti melakukan langkah antisipasi yaitu untuk penanggulangan kekurangan sebagaimana yang telah dilakukan peneliti sebelumnya. Untuk menanggulangi masalah perangkat pembelajaran jarak jauh ini menggunakan perangkat lunak yang cenderung lebih familiar dengan siswa. Perangkat tersebut misalnya penggunaan aplikasi whatapps yang dianggap sebagai hal yang biasa digunakan.

Sebelum menuju konsep E-learning, konsep learning atau pembelajaran juga dibahas di dalam jurnal oleh [15] dan [20] [15] memaparkan learning dalam 3 sudut pandang yakni learning dari Amerika Serikat dan Eropa Barat hingga learning menurut agama islam. Definisi belajar ada empat yaitu Learning is shown by a change in behavior as a results of experience, Learning is to observe, to read, to imitate, to try something themselves, to listen, to follow direction, Learing is a change in performance as a result of practice, Learning is the process by which an activity originates or is chaged training procedures (whether ini the laboratory or in training or in the natural invironment) as distinguished from change by factors not attributabel to training [15].

Sementara itu, untuk menguatkan hipotesis yang peneliti ajukan, bahwa terdapat pula kondisi positif antara penggunaan internet terhadap sikap, karakteristik siswa, dan sikap keagamaan. Pada bagian ini akan dibahas tentang relasi internet dan agama, banyak penulis yang membahas diantaranya [16], [17], [18], dan [19]. Beberapa penulis disini membahas internet sebagai kuasa atau kekuatan besar; [16] yang dikatakan [16] penggunaan internet dalam komunikasi agama merupakan tanda penting dari lahirnya kekuatan baru dalam kehidupan umat beragama karena mengubah tidak hanya metode enkulturasi agama dalam berbagai dimensinya. Di situ, internet memainkan peran pentingnya sebagai sarana untuk memuat informasi tentang sikap, karakter, dan agama yang bisa menimbulkan dampak.

Sementara itu, berkenaan dengan perlunya komitmen belajar dikemukakan komitmen terhadap tugas adalah suatu bentuk halus dari motivasi. Komitmen terhadap tugas bisa dipahami sebagai motivasi dari dalam diri yang dapat menjadi tenaga untuk memunculkan potensi yang dimiliki. Selain itu Hawadi dalam [20] mengemukakan dua faktor yang mempengaruhi komitmen terhadap tugas. Faktor individual mencakup persepsi terhadap diri, persepsi terhadap peran dan tugas, serta sikap orang tua [20] . Hal senada dikemukakan pula oleh peneliti lainnya seperti [12] dan [14]. 
Berdasarkan data dan kajian pustaka tersebut, maka dalam penelitian ini akan membahas pemenuhan aspek afektif siswa sekolah dasar melalui pembelajaran jarak jauh yang dilaksanakan dengan teknik asinkronus yang didahului dengan komitmen belajar pada masa pandemi Covid-19. Sehingga diharapkan akan memunculkan apakah terdapat perubahan sikap atau afektif siswa selama pembelajaran jarak jauh? Perubahan sikap peserta didik ini ditinjau dari sudut pandang orang tua, guru dan pendapat siswa terhadap keberlangsungan pembelajaran jarak jauh.

\section{METODOLOGI}

Isu pembelajaran jarak jauh dipilih sebagai isu penelitian atas pertimbangan adanya perdebatan yang sedang berlangsung antara pro dan kontra atas efektivitas pembelajaran jarak jauh yang membutuhkan pemahaman lebih lanjut. Kritik yang direspons dalam tulisan ini menyangkut ketidakmampuan pembelajaran jarak jauh memenuhi kompetensi afektif siswa. Sejalan dengan itu, penelitian ini dilakukan di sebuah Sekolah Dasar Negeri 138 Gegerkalong Girang di wilayah Kota Bandung Jawa Barat dengan mengevaluasi proses pembelajaran jarak jauh yang berlangsung. Kurikulum pembelajaran jarak jauh dikaji untuk melihat bagaimana dimensi afektif terdefinisikan dalam kurikulum [21].

Penelitian dimulai dengan presurvey untuk menentukan kelas yang dipilih dan juga mendapatkan izin dari pemegang otoritas Pendidikan di wilayah setempat. Responden dalam penelitian ini terdiri dari tiga kelompok. Pertama, guru yang dipilih berdasarkan kompetensi dan pengalaman mengajar. Kedua, orang tua murid sebagai pihak yang secara langsung berhadapan dan mengalami akibat pembelajaran jarak jauh. Ketiga, siswa yang dipilih sebenarnya mengikuti guru kelas yang dipilih.

Data dikumpulan melalui angket terhadap orang tua siswa, wawancara dengan guru, serta observasi terhadap kegiatan yang dilakukan siswa. Namun observasi ini tidak secara langsung oleh peneliti, melainkan observasi yang dilakukan orang tua siswa, yang hasilnya disampaikan kepada peneliti. Analisis data dimulai dengan reduksi data dalam bentuk pengolahan data responden yang berupa data ordinal menjadi data interval dengan methode succeesive interval (MSI) agar bisa data responden bisa dianalisis secara statistic. Data hasil penelitian selanjutnya dianalisis secara deskriptif. Sebagaimana yang disampaikan [22].

\section{HASIL DAN PEMBAHASAN}

1. Perubahan sikap siswa dari sudut pandang orang tua siswa

Pembahasan ini memaparkan tentang dampak pembelajaran jarak jauh dengan teknik asinkronus yang didahului komitmen belajar dalam pemerolehan kompetensi afektif siswa kelas VI pada salah satu sekolah dasar di kota bandung. Indikasi pemerolehan dan perubahan sikap atau afektif sebagaimana tabel berikut merupakan informasi dari laporan orang tua siswa kepada guru kelasnya.

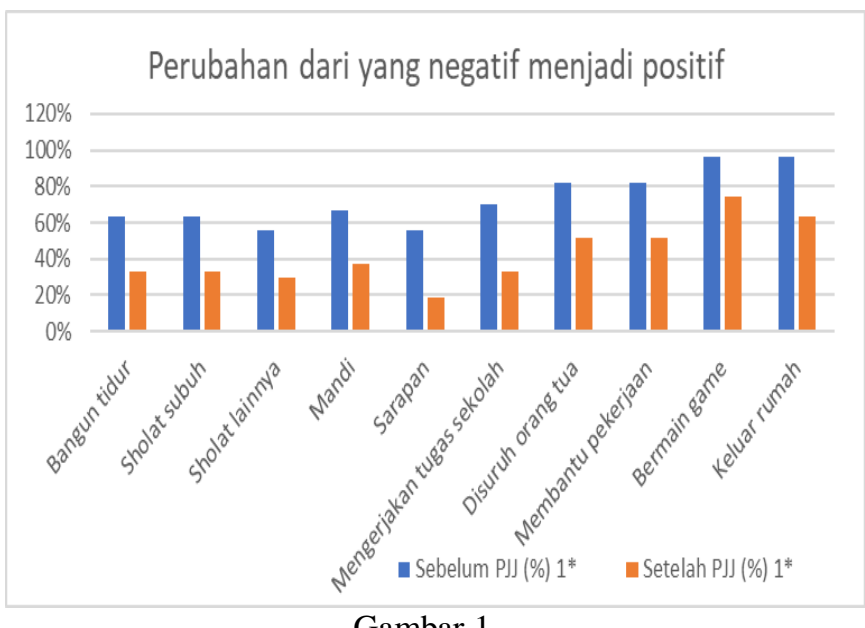

Perubahan Sikap Siswa di rumah

Berdasarkan tabel 1 tersebut terjadi perubahan sikap siswa dalam keseharian di rumahnya selama mengikuti kegiatan pembelajaran jarak jauh ini. Sebagai contoh siswa yang semula sering bangun terlambat sebanyak $60 \%$, setelah mengikuti arahan guru melalui pembelajaran jarak jauh yang didahului dengan komitmen belajar, menjadi sekitar $30 \%$ siswa yang masih terlambat. Hal ini menunjukkan terjadi peningkatan siswa yang menjadi lebih cepat bangun tidur dari sebelumnya. Hal tersebut juga terjadi pada aspek-aspek lainnya, mulai dari melaksanakan ibadah, mandi, melaksanakan tugas sekolah, membantu orang tua, maupun keinginan untuk bermain. Aspek terakhir, keinginan bermain yang semula sangat tinggi sekitar 90\%, setelah mengikuti pembelajaran jarak jauh yang didahului oleh komitmen belajar ini menjadi sekitar $60 \%$ siswa yang keinginannya untuk bermain. Hal ini menunjukkan adanya perubahan sikap yang positif.

Dari hasil temuan tersebut, dapat peneliti jabarkan bahwa sebagian besar siswa menunjukkan perubahan sikapnya ditinjau dari sudut pandang orang tua siswa. Hal ini, juga merujuk pada suatu pendapat tentang triangulasi dari orang tua siswa dimungkinkan untuk memperkuat informasi data dengan cara yang berbeda maupun data yang didapat dari lintas agar dapat mengurangi potensi penyimpangan yang bias terjadi pada penelitian seperti ini. Terlepas dari besaran persentase perubahan sikap siswa, dari kajian sikap-sikap negative peserta didik seperti sulit bangun pagi, sulit melaksanakan ibadah, malas mengerjakan tugas sekolah, atau keinginan keluar rumah yang tinggi, namun ketika pembelajaran jarak jauh ini didahului dengan komitmen antara guru, orang tua, dan peserta didik, akhirnya sikap-sikap tersebut memiliki kecenderungan berubah menjadi positif.

\section{Perubahan sikap siswa dari sudut pandang guru}

Sementara itu, perubahan sikap siswa menurut guru dalam pembelajaran jarak jauh ini agak berbeda. Hal ini karena guru tidak bisa melihat langsung perubahan sikap yang dialami 
siswa. Guru hanya bisa menafsirkan dari data yang didapat guru baik berupa foto proses siswa saat mengerjakan tugas dari guru maupun hasil kerja siswa. Walaupun tidak mengamati secara langsung para siswanya, namun mengamati melalui tugas yang disampaikan siswa serta proses siswa Ketika mengerjakan tugas dari gurunya. Hal ini dilakukan melalui pengiriman foto karya siswa dan foto siswa Ketika mengerjakan tugas tersebut. Dengan demikian walaupun guru tidak mengamati langsung, namun bisa menafsirkan dari fotofoto yang dikirimkan orang tua kepada guru. Berikut prosentase perubahan sikap siswa saat belajar atau mengerjakan tugas maupun kecepatan siswa dalam mengirimkan tugas.

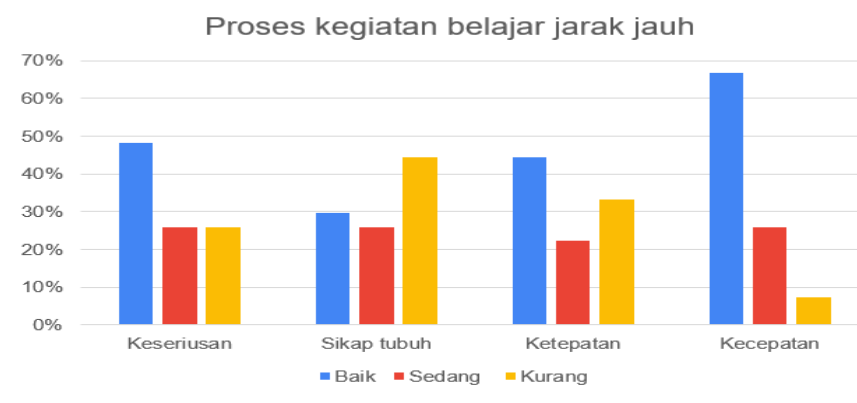

Gambar 2

Sikap siswa dalam mengerjakan tugas pembelajaran jarak jauh

Berdasarkan tabel tersebut tergambarkan bahwa dari empat aspek yang menjadi focus penilaian guru terhadap siswanya yaitu keseriusan, ketepatan dan kecepatan mengerjakan tugas, memiliki prosentase yang tinggi dengan kriteria baik. Hanya aspek sikap tubuh yang memiliki presentase kurang. Peneliti mengadakan cek silang terhadap guru dan mengamati fotofoto siswa ketika mengerjakan tugas. Hasil pengamatan terhadap gambar sikap tubuh, para siswa mengerjakan tugas dengan beragam pose, ada yang duduk tegak di meja, ada yang duduk lesehan, ada juga yang sambil telungkup. Kondisi sikap tubuh ini tidaklah mencerminkan sikap yang buruk, karena yang dimintakan guru adalah kenyamanan siswa selama mengerjakan tugasnya. Dengan demikian bisa sangat beragam. Berbeda dengan aspek lainnya seperti ketepatan dan kecepatan mengerjakan tugas. Pada aspek ini siswa sangat dituntut bekerja agar sesuai dengan kriteria guru. Namun pada aspek sikap tubuh, akan muncul kreativitas dan inovasi siswa.

Namun yang perlu diamati lebih mendalam adalah adanya ketidaksesuaian antara peningkatan dan perbaikan sikap siswa baik dalam keseriuan, sikap tubuh saat belajar, kecepatan dan ketepatan waktu, dengan keinginan siswa. Bahwa mayoritas siswa menginginkan pembelalajaran secara tatap muka, walaupun secara pembelajaran jarak jauh pun telah dapat membantu memperbaiki afektif siswa. Untuk menelaah ini peneliti menggunakan analisis data silang (crosstab analisys).

\section{Perubahan sikap siswa dari sudut pandang siswa}

Hal lain yang menjadi temuan selama pembelajaran jarak jauh ini adalah dari siswa. Hasil survey peneliti terhadap para siswa adalah untuk menggali refleksi siswa. Hasilnya tergambarkan dalam tabel berikut ini.
Respon siswa terhadap Pembelajaran jarak Jauh

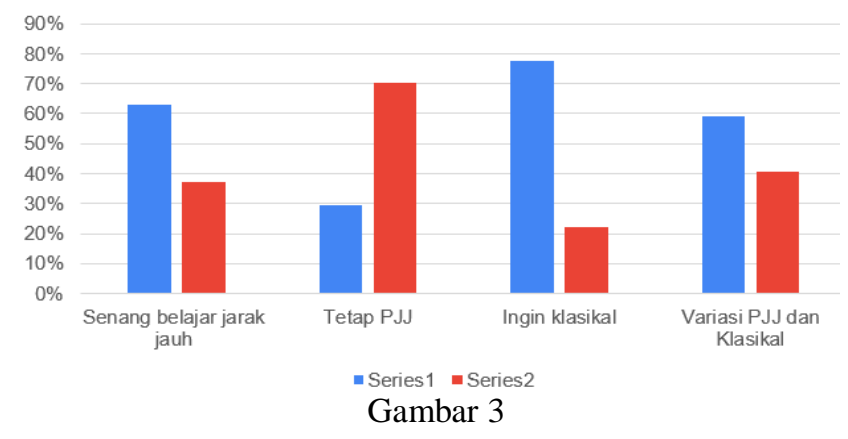

Sikap siswa terhadap pembelajaran jarak jauh

Berdasarkan tabel tersebut, hal yang menarik untuk ditelaah lebih mendalam adalah adanya anomali pikiran dan keinginan siswa. Sebantak $63 \%$ siswa merasa senang dengan pembelajaran jarak jauh. Namun hal ini bertolak belakang dengan keinginan siswa atas pembelajaran jarak jauh ini, ternyata sebanyak $70 \%$ siswa menolak untuk meneruskan pembelajaran jarak jauh. Demikian pula $78 \%$ siswa menginginkan untuk kembali belajar secara tatap muka. Sementara sebanyak 59\% siswa menginginkan pembelajaran bervariasi antara pembelajaran jarak jauh dengan tatap muka.

Dengan demikian, perubahan sikap siswa dari sudut pandang siswa sendiri menunjukkan bahwa mereka umumnya menyenangi belajar secara jarak jauh ini, namun mereka tetap ingin pula belajar secara tatap muka dan tidak ingin seterusnya secara jarak jauh. Teknik guru untuk mengawasi pembelajaran jarak jauh ini adalah dengan didahului kesepakatan atau komitmen belajar antara guru dan siswa dengan sepengetahuan orang tua siswa.

\section{IV.SIMPULAN}

Ternyata kajian yang selama ini menyatakan bahwa kebanyakan pembelajaran jarak jauh dianggap tidak atau kurang efektif untuk aspek afektif ternyata tidak terbukti, karena studi ini menemukan keberhasilan sebagaimana yang telah dikemukakan di atas yaitu terjadinya perubahan sikap siswa yang menjadi lebih baik walaupun pembelajaran jarak jauh dilaksanakan secara asinkronus. Namun keberhasilan pembelajaran jarak jauh ini karena dibantu dengan didahului kesepakatan dan komitmen belajar antara guru, orang tus siswa, dan siswa . Pelaksanaan pembelajaran jarak jauh secara asinkronus dengan pendekatan partisipatif orang tua telah memungkinkan ditemukannya hasil yang berbeda dibandingkan dengan asumsi awal bahwa akan sangat sulit mengubah perilaku atau kompetensi afektif jika dilakukan dengan pembelajaran jarak jauh. Karena itu, untuk memenuhi aspek afektif siswa walaupun pembelajaran dilaksanakan secara jarak jauh, maka dibutuhkan komitmen pembelajaran antara guru, siswa, dan orang tua siswa. Dalam hal ini, orang tua siswa berperan sebagai pengawas pelaksanaan pembelajaran di rumah.

Namun demikian, penelitian ini masih memiliki keterbatasan dalam hal keluasan subjek penelitian dan masa 


\section{- $=|P D|$ \\ Jurnal Pendidikan Dasar Indonesia \\ Volum 5 Nomor 2 bulan September tahun 2020. Page 40 - 44 \\ p-ISSN: 2477-5940 e-ISSN: 2477-8435}

penelitian yang singkat. Karena itu, masih dibutuhkan penelitian lanjutan untuk melengkapi dan meningkatkan akurasi dan signifikansi sehingga bisa digeneralisasikan.

\section{REFERENCES}

[1] Rahmawati, S. D. (2009). KENDALA PELAKSANAAN PEMBELAJARAN JARAK JAUH MELALUI INTERNET PADA MAHASISWA PJJ S1 PGSD UNIVERSITAS NEGERI SEMARANG. Unnes Semarang.

[2] Farisi, M. I. (2020). Karakter dan pengembangannya dalam sistem pendidikan jarak jauh. FKIP UT, (107).

[3] Gazali, E. (2018). KENDALA PEMANFAATAN INTERNET SEBAGAI MEDIA PEMBELAJARAN JARAK JAUH ( FENOMENOLOGI KOMUNITAS HOMESCHOOLING. Pascasaraja Universitas Prof. Dr. Moestopo, V(1), 10-31.

[4] Holotescu, C., Grosseck, G., \& Danciu, E. (2014). Educational digital stories in 140 characters : towards a typology of micro-blog storytelling in academic courses. Procedia - Social and Behavioral Sciences, 116 4301-4305. https://doi.org/10.1016/j.sbspro.2014.01.936

[5] Chertoff, J. D., Zarzour, J. G., Morgan, D. E., Lewis, P. J., Canon, C. L., \& Harvey, J. A. (2020). The Early Influence and Effects of the COVID-19 Pandemic on Resident Education and Adaptations. Journal of the American College of Radiology. https://doi.org/10.1016/j.jacr.2020.07.022

[6] Vu, C., Hoang, A., \& Than, V. (2020). Dataset of Vietnamese teachers' perspectives and perceived support during the COVID-19 pandemic, 31. https://doi.org/10.1016/j.dib.2020.105788

[7] Kumar, P., Dawman, L., Panda, P., \& Kumar, I. (2020). Seizure European Journal of Epilepsy Feasibility and e ff ectiveness of teleconsultation in children with epilepsy amidst the ongoing COVID 19 pandemic in a resource-limited country. Seizure: European Journal of Epilepsy, 81(July), 29-35. https://doi.org/10.1016/j.seizure.2020.07.013

[8] Carolan, C., Davies, C. L., Crookes, P., Mcghee, S., \& Roxburgh, M (2020). Nurse Education in Practice Guest Editorial education. Nurse Education in Practice, 46(May), 102807 https://doi.org/10.1016/j.nepr.2020.102807

[9] Jamaluddin, D., Ratnasih, T., Gunawan, H., \& Paujiah, E. (2020). Pembelajaran Daring Masa Pandemik Covid-19 Pada Calon Guru : Hambatan, Solusi, dan Proyeksi. LPPM UIN SGD.

[10] Setiawan, A. R. (2020). Lembar Kegiatan Literasi Saintifik untuk Pembelajaran Jarak Jauh Topik Penyakit Coronavirus 2019 (COVID19), 2(1), 28-36.

[11] Wulandari, H., \& Purwanta, E. (2020). Pencapaian Perkembangan Anak Usia Dini di TK selama Pembelajaran Daring saat Pandemi Covid-19 Abstrak. Jurnal Obsesi : Jurnal Pendidikan Anak Usia Dini, 5(1), 452-462. https://doi.org/10.31004/obsesi.v5i1.626

[12] Arbaa, R., Jamil, H., \& Razak, N. A. (2010). Hubungan Guru-Pelajar dan Kaitannya dengan Komitmen Belajar Pelajar: Adakah Guru Berkualiti Menghasilkan Perbezaan Pembelajaran antara Jantina Pelajar? Jurnal Pendidikan Malaysia, 35(2), 61-69.

[13] Rosdiana, D. (2013). PENGARUH KOMPETENSI GURU DAN KOMITMEN MENGAJAR TERHADAP EFEKTIVITAS PROSES PEMBELAJARAN SERTA IMPLIKASINYA PADA HASIL BELAJAR SISWA DALAM MATA PELAJARAN EKONOMI Dian Rosdiana. Jurnal Penelitian LPPM UPI, 2.

[14] Hakim, A. R. (2016). Prestasi belajar matematika ditinjau dari sikap dan komitmen diri peserta didik pada pelajaran matematika. JKPM Universitas Indraprasta PGRI Jakarta, 02(01), 24-36.

[15] Baroroh, R. U. (2004). PROSES BELAJAR MENGAJAR DAN APLIKASINYA DALAM PEMBELAJARAN PENDIDIKAN AGAMA ISLAM. UIN Kalijaga.

[16] Abdullah, I. (2017). DI BAWAH BAYANG-BAYANG MEDIA:Kodifikasi, Divergensi, dan Kooptasi Agama di Era Internet. Sabda, 12, 116-121.

[17] Husna, A. Y. (2016). Pemanfaatan Media Pembelajaran Berbasis Komputer dan Internet oleh Guru PAI SMPN 1 Gondang. Disertasi IAIN Tulung Agung, 66-117.

[18] Kruger, O. (2005). Discovering the invisible internet. Heidelberg Journal of Religions on the Internet, 1, 75-76.
[19] Hackett, R. I. J. (2006). Religion and the Internet. ISSN 0392-1921, 67-76. https://doi.org/10.1177/0392192106069015

[20] Amini, M., Mayangsari, M. D., Zwagery, V., Psikologi, P. S Kedokteran, F., Mangkurat, U. L., ... Selatan, K. (2019). TUGAS PADA MAHASISWA PROGRAM STUDI PSIKOLOGI THE RELATIONSHIP BETWEEN1SELF6DIRECTED LEARNING AND TASK COMMITMENT AMONG PSYCHOLOGY STUDENT, 2 149-152.

[21] Balitbangperbukuan. (2020). KOMPETENSI INTI DAN KOMPETENSI DASAR PELAJARAN PADA DASAR , DAN PENDIDIKAN MENENGAH BERBENTUK SEKOLAH MENENGAH ATAS UNTUK KONDISI KHUSUS KOMPETENS INTI DAN KOMPETENSI DASAR PELAJARAN PADA KURIKULUM 2013. Kemdikbud.

[22] Sugiono. (2007). Metode Penelitian Pendidikan; Pendekatan Kuantitatif, Kualitatif dan R\&D. Alfabeta, Bandung, 2007. Retrieved from Alfabeta, Bandung 